\title{
Mapas curriculares: prisão, escola e sentidos do conhecimento
}

\author{
Cátia Alvisi*
}

\begin{abstract}
Resumo
Procura-se neste texto discutir o currículo de uma escola situada dentro de uma instituição prisional. Nesse sentido, a pesquisa de doutorado (2011-2015) buscou apoio na etnografia como forma de aproximar-se do cotidiano escolar cartografando suas práticas e atribuindo sentidos aos modos de se "fazer currículo". Através do diário de bordo e das entrevistas realizadas com os alunos presos, foi possível construir um mapa desse currículo encarcerado bem como identificar sentidos atribuídos ao conhecimento nesse ambiente. A imersão ao campo por oito meses, a participação nas aulas e nas atividades do universo prisional, possibilitaram a compreensão do currículo sob a ótica dos presos e suas demandas sobre o que se deve ou não ser ensinado na escola.

Palavras-chave: Escola; Prisão; Educação de Jovens e Adultos.
\end{abstract}

\section{Curriculum maps: prison, school and meanings of knowledge}

\begin{abstract}
The aim of this text is to discuss the curriculum of a school located within a prison institution. In this regard, doctoral research (2011-2015) found support in ethnography as a way to approach the school routine charting its practices and giving way to the ways of "doing curriculum". Through the logbook and interviews with the arrested students it was possible to construct a map of this imprisoned curriculum and identify meanings attributed to knowledge in this environment. Immersion in the field for eight months, participation in classes and activities in the prison environment allowed the understanding of the curriculum from the perspective of prisoners and their demands on what should or should not be taught in school.
\end{abstract}

Keywords: School; Prison; Youth and Adults Education (YAE).

A temática da educação prisional no Brasil entra em cena recentemente, com mais força com a publicação das Diretrizes Nacionais para a oferta de educação de jovens e adultos em situação de privação de liberdade nos estabelecimentos penais (BRASIL, 2010). O documento apresenta avanço para a área de políticas públicas, para a educação prisional e atribui responsabilidades aos Estados para sua efetivação. $\mathrm{Na}$ pesquisa de doutorado concluída no ano de 2015 observou-se a passagem da maneira como a educação prisional era administrada no Estado de São Paulo. Desde a década de 80 estava sob a responsabilidade da Fundação Prof. ${ }^{\circ}$ Doutor Manoel Pedro Pimentel (FUNAP), passando em 2013 para a Secretaria de Estado da Educação.

Para compreender o lugar da educação prisional e seus sentidos é necessário uma análise do lugar que a prisão e os presos ocupam em tempos de globalização. Importante salientar também que o debate sobre a conjuntura das prisões, de certo modo, está fortemente marcado pelos ecos dos ajustes neoliberais da década de 1990. Ajustes que marcaram a política do final do século $\mathrm{XX}$ não apenas no Brasil, mas em diferentes partes do mundo e que contribuíram para o enfraquecimento do Estado Social e fortalecimento do Estado Penal.
No caso específico da temática desse artigo, essa mudança na maneira de administrar a criminalidade pode também ser entendida como a "penalização da miséria" como já sinalizava Wacquant (2008). Nesse sentido, o endurecimento das penas soma-se com a preocupação em construir novos espaços para o destino da população excedente, ou ainda do "lixo humano" (BAUMAN, 2007). Portanto, tratar da temática prisional em nosso país é tratar da miséria humana apontando para uma parcela da população, que dificilmente obteve algum benefício do Estado Social, mas ao contrário tem se tornado as figuras centrais para o fortalecimento do Estado Penal. Assim sendo, quando verificamos os dados da população penitenciária brasileira e os índices de estudo apresentados por esta população verificamos que 622.202 pessoas estão presas no Brasil (Sistema Integrado de Informações Penitenciárias - InfoPen dezembro de 2014). Buscando uma aproximação acerca do perfil desses sujeitos e, em especial, do que aqui queremos problematizar, ou seja, a negação de direitos sociais a esses sujeitos, como por exemplo, o direito à educação, é possível constatar que do total de presos no país, 216.870 possuem Ensino Fundamental incompleto. E os dados continuam: 471.254 é a população carcerária

\footnotetext{
*Endereço Eletrônico: catialvisi@gmail.com
} 
entre 18 e 24 anos. Segundo Julião (2009) e Adorno (1991) os dados disponíveis não parecem adequados para tratamento científico. Desta maneira, tornam-se frágeis já que "cada Estado utiliza-se de mecanismos muitas vezes, antiquados, irracionais e ultrapassados" (JULIÃO, 2009, p. 80). Da mesma forma, a crítica feita por Adorno (1991) coloca questões ainda mais alarmantes. Para este autor, a questão não perpassa apenas por "ausência de recursos humanos qualificados ou da falta de métodos racionais de trabalho [...]". Destaca que essas confusões parecem dispor de certa intencionalidade.

A ideia de "penalidade neoliberal" discutida por Wacquant (2008) nos acompanha para situar a análise macro da situação prisional no Brasil. O autor traça um paralelo indicando que os países da América Latina têm buscado a réplica do modelo americano de punição "importando-o ao atacado" (WACQUANT, 2008, p. 100). Busca ainda sustentar sua ideia apoiando-se em Michel Foucault quando aponta para um "governo da insegurança social". E explica:

Esse novo governo [...] assenta-se por um lado, no disciplinamento do mercado de trabalho desqualificado e desregulado, e por outro, em um aparato intrusivo e onipresente. Em países onde a ideologia neoliberal de submissão ao "livre mercado" se implantou, observamos um espetacular crescimento do número de pessoas colocadas atrás das grades, enquanto o Estado depende cada vez mais da polícia e das instituições penais para conter a desordem produzida pelo desemprego em massa, a imposição do trabalho precário e o encolhimento da proteção social (2008, p. 96).

Os dados gerados pelo Infopen mesmo com todos os problemas nas formas de sua produção, desafiam os governos a assegurarem o direito humano à educação como um direito de base para a garantia de outros direitos dentro da realidade carcerária. Vale aqui um primeiro esclarecimento: a Lei de Execução Penal (LEP n7.210/84), considerada uma das avançadas do mundo por juristas da área propõe as condições em que o encarcerado cumprirá sua pena. Além do mais, a LEP propõe a desfederalização do Direito Penal. Com isso, cada Estado possui autonomia para desenvolver suas formas de Execução Penal. Assim, dez anos após a aprovação da Lei de Execução Penal (LEP) cria-se o Fundo Penitenciário Nacional (Funpen) pela Lei Complementar $\mathrm{n}^{\circ} 79$, de
7 de janeiro de 1994 e uma década antes (junho de 1980) instala-se o Conselho Nacional de Política Criminal e Penitenciária (CNPCP), este último considerado o primeiro dos órgãos quando nos referimos a Execução Penal. É possível visualizar estas informações no site ${ }^{1}$ do Ministério da Justiça quando são expostas quais as funções apontadas na LEP que o Departamento Penitenciário Nacional (DEPEN) deve cumprir. Desta forma, quando tratamos da Execução Penal brasileira temos o DEPEN que deve gerir os recursos do FUNPEN e também apoiar o CNPCP com questões administrativas e financeiras.

A composição da estrutura federal para o campo prisional e a Lei de Execução Penal (LEP/ ${ }^{\circ}$ 7.210/84) conforme destacamos acima, considerada avançada nas temáticas propostas não encontra ecos e articulações dentro dos Estados Brasileiros. Sabemos da autonomia que os Estados brasileiros têm nas formas de como realizar a Execução Penal, porém o que se encontra é um quadro de total sucateamento dentro dos estabelecimentos penais e a LEP dificilmente pode ser cumprida por falta de condições.

Realizando um recorte para o Estado de São Paulo, local onde se situa a unidade prisional pesquisada, é possível encontrar dados que também apontam para uma grande lacuna entre o que propõe a Lei de Execução Penal e a realidade intramuros das unidades prisionais paulistas. $\mathrm{O}$ site oficial do Estado de São Paulo ${ }^{2}$ orgulha-se ao situar o Estado como o "motor econômico" e "mais rico" dentre as unidades federativas. Enumera ainda outras qualidades tais como: responsável por $31 \%$ do Produto Interno Bruto (PIB) do país e por possuir a melhor infraestrutura e mão de obra qualificada. Entretanto, o que não é motivo de orgulho e não aparece em nenhum link do site são os dados de sua realidade carcerária. Assim estampa-se a realidade prisional do Estado de São Paulo pelo Infopen (junho 2014): 219.053 presos, os quais representam $40 \%$ da população carcerária do país. A faixa etária da população é assustadoramente jovem situando-se entre 18 a 24 anos, assim como a média nacional já apontada. A predominância no modo de cumprimento da pena é o regime fechado, responsável por 93.228 encarcerados. No Brasil, segundo relatório da Unesco (2009), 95\% da população prisional não precisaria de regime fechado e, sendo assim, 30\% da população prisional poderia estar cumprindo penas alternativas. Ao compararmos o Brasil com a Europa quanto ao assunto, temos $10 \%$ de aplicação de penas 
alternativas em nosso país, ao passo que na Europa $70 \%$. Mas de volta ao "motor econômico" do Brasil, fechamos os dados com 69.926 encarcerados com Ensino Fundamental incompleto. Desse número, apenas 14.359 encontra-se em atividades educacionais.

Para Bauman (2008) a quantidade de seres humanos tornada excessiva pelo triunfo do capitalismo global produz um "lixo humano" que precisa ser destinado aos aterros (prisões). A retração de serviços sociais e o endurecimento das penas promovem consequências na maneira de focar o problema da segurança pública: é preciso expandir os aterros para receber o "lixo humano", porém seu tratamento inviabiliza sua "reciclagem social". Ainda para Bauman (2008, p. 76):

Os criminosos [...] não são mais vistos como temporariamente expulsos da vida social normal e destinados a serem "reeducados, reabilitados e reenviados" à comunidade na primeira oportunidade- mas como permanentemente marginalizados, inadequados para a "reciclagem social" e designados a serem mantidos permanentemente fora, longe da comunidade dos cidadãos cumpridores da lei.

A Secretaria de Segurança Pública do "motor econômico" do país estampa no site seu plano de expansão das unidades prisionais em pleno andamento e lá encontramos a seguinte afirmação: "São Paulo conta hoje com a polícia que mais prende no Brasil, fruto da política séria adotada pelo governador Geraldo Alckmin"3.

Não estamos discutindo a não necessidade da construção de novos aterros/presídios, pois afinal em um ambiente de hiperinflação carcerária, tornam-se quase impossíveis ações triviais de higiene e torna-se ainda mais distante a possibilidade de executar a Lei de Execução Penal em situações de superlotação. Ainda por informações disponibilizadas no site "Observatório de Segurança Pública" destaca-se São Paulo também por ser o estado que possui o maior número de estabelecimentos prisionais (149).

É interessante notar como os jogos de linguagem (FOUCAULT, 1996 apud VEIGA NETO, 2007) dispostos em redes discursivas operam de maneira interligada aos choques imagéticos (TURCKE, 2010) disparados para a população. Logo, veem-se ao vivo cenas horripilantes de terror, medo e violência na mídia televisiva criando a necessidade de nos sentirmos seguros das classes perigosas como pobres, não produtivos e não consumidores do mercado. Deste modo, a estratégia de lucrar com o medo, como assinala Bauman $(2008$, p. 23) "está lá, saturando diariamente a existência humana, enquanto a desregulamentação penetra profundamente nos seus alicerces e os bastiões da defesa civil da sociedade desabam".

Wacquant (2008) em suas análises sobre a penalidade neoliberal, já apontada neste texto anteriormente, procura sinalizar que o fortalecimento do Estado Penal é questão de escolha política. Em nosso caso, o Estado de São Paulo tem procurado investir cada vez mais na repressão e militarização como a solução mais viável à resposta as ondas de "violência urbana". Trata-se de manter a "lei e a ordem" excluindo da discussão formas de tratar a "insegurança social e econômica" (p. 104) que marcam "os estratos destituídos da classe operária- o desempregado, o precariamente empregado e o imigrante recente" (p. 105).

Nesta primeira parte do texto procurei circunscrever a realidade carcerária para que possamos entrar aos poucos por entre as grades e entender a complexa teia de relações para que uma escola funcione dentro de uma unidade prisional.

\section{A escola da prisão}

A entrada em uma unidade prisional para realização de uma pesquisa é uma tarefa desgastante. É preciso que o projeto de pesquisa seja aprovado pelo Comitê de Ética em Pesquisa da Secretaria de Administração Penitenciária e esse processo, no meu caso, demorou seis meses. Após a aprovação, a Vara de Execução Penal da cidade em que se situa a prisão recebe a autorização e o Juiz de Execução Penal deve liberar o pedido para que então a pesquisadora possa fazer contato com a Equipe Dirigente da unidade prisional. Após todos esses trâmites deu-se início a pesquisa etnográfica por oito meses. Numa perspectiva etnográfica a produção dos dados através do diário de campo ganha muita importância, pois ao descrevermos o que vimos, ouvimos e observamos colocamos na escrita muitas das vozes presentes no campo. Essas outras vozes fazem com que o diário de campo seja entendido como um texto polifônico no sentido atribuído por Bezerra (2005, p. 194) para o qual "o que caracteriza a polifonia é a posição do autor como regente do grande coro de vozes que participam do processo dialógico". Sendo assim, a produção dos diários de campo durante os oito meses da pesquisa procuraram trazer essas vozes 
como partes fundamentais no processo de descoberta do território.

A entrada a campo num primeiro momento me fez imergir em uma realidade muito pouco conhecida e muito peculiar por se tratar de uma instituição em que a disciplina no sentido foucaultiano (dos saberes e corpos) opera num curto circuito que mantém a instituição penal em funcionamento. Poderíamos entender que a disciplina é naturalizada e exercida não em polos dicotômicos (corpo dirigente/ condenados), mas numa relação muito mais complexa e rizomática. Logo, eu também fazia parte desse rizoma, dessa rede em que as pistas que ia encontrando pelo caminho produziam sentidos para a produção dos dados da pesquisa.

Assim, durante a navegação, a construção dos mapas da realidade pesquisada foram me mostrando o sentido de seus contornos e linhas. A realidade prisional me afastava cada vez mais de se mostrar apenas como rotina e me alertava que tudo "não passa de um concentrado de significação, de saber e de poder" (PASSOS; KASTRUP; ESCÓSSIA, 2009, p. 10).

A escolha pela etnografia me permitiu acompanhar a processualidade de ações tão peculiares e próprias da comunidade pesquisada. E o mais interessante e instigador é que essas experiências vividas iam configurando o método, revelando em que deveria apostar e em que deveria deixar de lado para compor o estudo.

Sendo assim, a questão da escrita do diário de campo é uma ferramenta central para a prática da etnografia, já que possibilita registrar as "teias de significado" com os quais os grupos se "prendem" à sua cultura (PASSOS; KASTRUP; ESCÓSSIA, 2009 p. 15). Desta forma, o registro escrito objetivou traçar o caminho da navegação dos lugares por onde nunca havia passado, mas que já existiam e eram habitados.

Acompanhei aulas desde classes de alfabetização ao Ensino Médio. Logo que iniciei a pesquisa de campo, a responsabilidade pela oferta e funcionamento da educação era da FUNAPFundação Prof ${ }^{\circ}$ Doutor Manoel Pedro Pimentel, que quando criada (1976) tinha como função central ofertar trabalho remunerado aos presos. A partir do inicio da década de 80, a Secretaria Estadual de Educação se exime da responsabilidade pela educação nas prisões paulistas e a FUNAP sem recursos para assumir tal função, cria a estratégia dos monitores-presos. Para assumir a função de monitor-preso é preciso passar por uma seleção por algum representante da FUNAP. A preferência se dá para presos que já possuam o Ensino Médio. Esses presos recebem $3 / 4$ do salário mínimo e a remição de pena por trabalho. Essa foi a cena que perdurou até 2013, quando por pressão do Ministério Público, a Secretaria de Estado da Educação de São Paulo retoma sua responsabilidade pelo funcionamento das escolas das prisões paulistas.

Desta forma pude conviver com os monitores-presos que eram "professores" por algumas horas de seus parceiros de cela e também acompanhei a chegada dos professores "da rua", como os presos diziam, no início do ano de 2013.

Quando de responsabilidade da FUNAP, para que o preso obtivesse certificação pelo estudo era preciso que realizasse avaliações como ENCEJA (Exame Nacional para Certificação de Competências de Jovens e Adultos) e ENEM (Exame Nacional do Ensino Médio) e caso não obtivesse êxito, continuava estudando até conseguir o resultado pelas avaliações. Com a chegada da Secretaria Estadual, a parte de documentação do aluno fica a cargo de uma escola estadual "na rua", chamada de vinculadora. Desta maneira, quando o preso consegue a liberdade, procura pela escola vinculadora para retirar sua certificação e histórico.

Essa passagem da FUNAP para a Secretaria Estadual encontra ainda muitos pontos para serem acertados, e um deles, como exemplo, é ressignificar o papel da escola vinculadora que se configura apenas como a organização da parte burocrática. A escola vinculadora não incorporou para seu projeto político pedagógico o funcionamento de uma sala dentro de uma prisão. Além do mais, os professores que trabalham nas unidades prisionais participam na escola vinculadora de uma reunião semanal para discutir questões pedagógicas, entretanto a realidade da prisão não é trazida para a discussão.

Outra questão com impacto forte na questão curricular é a formação do professor. Por uma estratégia, a meu ver, as aulas são oferecidas apenas a professores da categoria $\mathrm{O}$ (com contrato determinado) e não para professores titulares de cargo. Com isso, a cada semestre, o contrato é interrompido e novas contratações são realizadas.

A pesquisa evidenciou o que os dados do INFOPEN já mostraram: os alunos em situação de privação de liberdade possuem apenas o Ensino Fundamental incompleto em sua maioria, possuem uma trajetória interrompida marcada pela repetência e evasão. Nesse sentido, pensar a formação do profissional configura-se como um dos eixos das 
Diretrizes Nacionais (BRASIL, 2010) para a oferta de educação de jovens e adultos em situação de privação de liberdade nos estabelecimentos penais como forma de trazer qualidade para o processo de ensino aprendizagem.

Vale ressaltar que no Estado do Pará, a Secretaria Estadual da Educação para resolver a questão da valorização dos profissionais envolvidos na oferta de educação na prisão, que são quadro permanente da rede, paga $50 \%$ a mais sobre o salário básico, como adicional de periculosidade.

Percebe-se que muitas são as questões de estrutura que precisam de um plano de trabalho estruturado pela Secretaria de Estado de Educação para que a educação prisional se institua como política pública e não como um Programa Estadual de Educação nas Prisões (Decreto Estadual $\mathrm{n}^{\circ}$ 57.238/2011), maneira pela qual foi implantado.

Nesse sentido, quando me proponho a investigar a configuração do currículo dentro de uma unidade prisional pretendo compreendê-lo como uma construção social imerso em uma rede de discursos que se movimentam e produzem efeitos de sentido sobre as práticas curriculares tecidas no espaço. Portanto, me afasto da concepção de discurso como um signo (SAUSSURE, 2000) que representa a fala, mas sim como produtor e instituinte de regimes de verdade que controlam e moldam nossas maneiras de fazer funcionar $\mathrm{o}$ mundo.

Ainda procurando circunscrever a maneira pela qual opero com a noção de discurso, e aqui, o de um discurso curricular que configura uma escola prisional, recorro às palavras de Foucault (2008, p. 12):

Cada sociedade tem seu regime de verdade, sua "política geral da verdade", isto é, os tipos de discurso que ela aceita e faz funcionar como verdadeiros; os mecanismos e as instâncias que permitem distinguir os enunciados verdadeiros dos falsos, a maneira como se sancionam uns e outros; as técnicas e os procedimentos que são valorizados para a obtenção da verdade, o estatuto daqueles que tem a função de dizer o que funciona como verdadeiro.

No Brasil, a publicação de recentes documentos sobre a oferta de Educação nas Prisões coloca esta temática tão opaca e sombria como um tema que deve ser tratado. E colabora também para que esses documentos entendidos como dispositivos discursivos façam "funcionar" a educação prisional. O objetivo da Diretriz publicada é apresentar elementos para a definição de uma política macro e não para particularidades regionais e/ou institucionais que deverão ser resolvidas localmente à luz das orientações contidas no Parecer e na Resolução " (n², de 19/05/2010). A Diretriz se preocupa em delinear ações macro porque como já descrito é função de cada Estado organizar sua política, mas sugere eixos para atenção. São eles: Eixo A - gestão, articulação e mobilização; Eixo B formação e valorização dos profissionais envolvidos na oferta da educação prisional; Eixo C - aspectos pedagógicos.

Torna-se importante então problematizar sobre as políticas de currículo enquanto resultantes de processos de lutas pela definição de qual conhecimento é valido ou não dentro de um espaço educativo. Nesse sentido, não defendo a separação binária de que o Estado seja visto como produtor de políticas cabendo as escolas implementá-las, porém não descarto também a relação de que toda política curricular está imbricada em processos sociais, econômicos e culturais que são intermediados pelo Estado (LOPES, 2006). Ao não conceber essa relação como binária, aponto para a prática das escolas como locais de lutas para significação das políticas curriculares afastando a ideia de encará-las como o lugar subordinado da implementação dessas políticas curriculares, mas sim ocupando centralidade na produção de novos sentidos para essas políticas. Assim sendo, procuro olhar para esta diretriz curricular para a educação prisional na busca por compreender as teias de significações e colocá-la num jogo discursivo que "está imbricado em instituições, processos econômicos e culturais, normas e técnicas que constituem as relações sociais" (LOPES, 2006, p. 8).

Desta forma, os itens que serão sinalizados no texto da diretriz devem ser lidos como terrenos de areia movediça, já que procuram instaurar direcionamentos que por onde passam serão recontextualizados. Aqui a opção pela palavra recontextualização se aproxima a de um "telefone sem fio". Esta é uma brincadeira em que uma palavra é dita pela primeira pessoa de uma fila, no ouvido da segunda e ao terminar de ser repassada às pessoas presentes na brincadeira, a palavra original, primeira a ser pensada, muitas vezes torna-se uma nova palavra quando a última pessoa da fila diz em voz alta qual é a palavra que ouviu. É com este sentido que vejo as políticas de currículo. Assim sendo, conforme a própria diretriz sinaliza, seu objetivo é orientar ações nacionais a fim de garantir a oferta da educação prisional. Salienta-se, portanto, 
mais uma vez que a diretriz precisa encontrar uma estrutura em cada Estado, tornando-a política de Estado e não ação pontual e dispersa dentro da heterogeneidade do sistema prisional.

Por fim, quando observamos os caminhos que o Estado de São Paulo escolheu para "assumir", entre aspas, a responsabilidade pela oferta da educação prisional encontramos um processo com várias lacunas que vão desde a atribuição das aulas, como já mencionado, pela escolha na opção por um Programa de Educação Prisional e não como política instituída. Um Programa pode ser implantado bem como ser extinto a qualquer momento. E isso torna frágil qualquer ação educativa que passa a ser fragmentada e sem planejamento.

A passagem da FUNAP para a Secretaria de Estado da Educação de São Paulo (SEE) foi bastante tumultuada como veremos nos trechos a seguir em que os presos colocam os impasses e as contradições vividas. Leão, na época um monitorpreso da FUNAP estava à espera das comandas vindas pela SEE. A primeira delas, após receberem na unidade prisional a visita da Diretora da escola vinculadora, foi a orientação para a matrícula dos presos. O monitor-preso em uma das entrevistas faz a seguinte observação: "Não existe transição e sim ruptura". O que Leão queria evidenciar é que a FUNAP encerraria sua parte na Educação e ficaria tudo para a Secretaria da Educação resolver. Conta também que a primeira orientação foi a de que para efetivar matrícula e ser certificado ao final do semestre letivo, o aluno deveria ter obrigatoriamente os seguintes documentos: RG, certidão de nascimento ou casamento, histórico escolar. Alerta também que esses documentos devem estar legíveis para serem aceitos. Essa foi a primeira indignação por parte de Leão que coloca: "Olha, eu to achando bom a Secretaria da Educação assumir... mas espera aí... aqui é diferente de uma escola da rua nesse sentido da documentação. A maior parte aqui não tem esses documentos, tem gente que nem recebe visita de família, gente de outro Estado... eu vou começar agora a fazer um levantamento da documentação deles pra começar a pedir. Mas não podemos matricular sem ter esses documentos".

Estava presente quando Leão deu a notícia para Sílvio, um preso interessado em realizar a matrícula quando respondeu: "Engraçado... o Estado não te dá condições... ele pede pra um aleijado andar... olha... você quer estudar... estuda... só que precisa do RG... Acho que poucas pessoas sabem, mas todo mundo que vai preso, a maioria dos documentos é tudo extraviado, entendeu...".

A fala de Silvio evidencia um desconhecimento da SEE em lidar com a questão da Educação Prisional. Criam-se as regras e não se discutem maneiras de resolver a questão. Silvio conclui: "o que falta aqui é aquele cara interessado nessa melhoria né... porque nós temos a Delegacia Seccional, se tem uma pessoa que vai lá e fala: nós temos tantos presos aqui sem $R G$, e tantos presos que estão no semiaberto perto de voltar pra rua e precisam acertar seus documentos... Pô... intenção não é ressocializar?".

Outro momento que pude vivenciar é quando chegou o calendário escolar. Os monitorespresos se divertiam com a informação que constava: "Reunião de Pais".

A fala de Leão nos indica que pensar o funcionamento da escola na prisão não pode passar pela simples "cópia" do modelo educativo oferecido na rua apagando todas as questões que significam a privação da liberdade. Por exemplo, a problemática da documentação acabou por impedir muitos alunos de iniciarem o semestre letivo. Deste modo, tive acesso aos relatórios que disponibilizam a quantidade de presos estudando e os que estavam aguardando vaga. No item aguardando vaga podemos considerar esses casos de documentação incompleta. Assim temos no inicio de 2013 (fevereiro), oitenta e oito (88) presos estudando (entre Ensino Fundamental e Médio) e noventa e dois (92) aguardando vaga. Três meses depois, em outro relatório temos uma população prisional com duzentos e quarenta e um (241), dos quais noventa e dois estudando (92) e noventa e cinco (95) aguardando vaga.

A motivação inicial dos alunos em situação de privação de liberdade para a responsabilidade pela SEE era a de que a parte da certificação iria ser garantida, mas desconfiavam das intenções dessa mudança conforme nos aponta Wellington: "Sabe... quando eu vi que ia mudar da FUNAP pra Secretaria de Educação e ia aumentar o número de horas de aula eu pensei assim: Será que realmente eles fizeram isso pra realmente ensinar a gente ou só pra soltar mais logo e desocupar o espaço que tá lotado... não tem mais espaço... onde eu tava em Hortolândia não tinha espaço pra dormir não... eu já vim pra cá pensando nisso... Pensar em colocar uma escola lá dentro? Como? Sem condições? Mas eu penso que se é pra ensinar a gente realmente pra tentar mudar ou pra soltar?". 
A fala de Wellington coloca mais uma vez os jogos discursivos presentes na configuração de um currículo para a escola do cárcere. Com isso quero dizer que a instituição prisional demarca práticas discursivas sobre quem a habita e nesse sentido, o que entende por conhecimento e como significá-lo.

\section{Sentidos do conhecimento}

Circunscrever o currículo de forma ampla ultrapassando a ideia de guia curricular é uma possibilidade de colocá-lo em meio a discursos que se adéquam para atender determinadas demandas, urgências e modos de governar. Nessa perspectiva, a linguagem ocupa um lugar central, já que a produção dos discursos sobre o currículo pode evidenciar suas conexões e estratégias para fazer valer como Verdade este ou aquele tipo de conhecimento.

Nesse sentido, entendo o currículo como texto e como discurso dentro da escola prisional como um dispositivo de governamentalidade. A governamentalidade é definida por Foucault (2008, p. 144) como:

O conjunto constituído pelas instituições, procedimentos, análises e reflexões, os cálculos e táticas que permitem exercer essa forma bastante específica, embora muito complexa de poder que tem por alvo principal a população, por principal forma de saber a economia política e por instrumento técnico essencial os dispositivos de segurança. Em segundo lugar, por "governamentalidade" entendo a tendência, a linha de força que, em todo o Ocidente, não parou de conduzir, e desde há muito, para a preeminência desse tipo de poder que podemos chamar de "governo" sobre todos os outrossoberania, disciplina- e que trouxe, por um lado [e por outro lado], o desenvolvimento de toda uma série de saberes. Enfim, por "governamentalidade" creio que se deveria entender o processo, ou antes, o resultado do processo pelo qual o Estado de justiça da Idade Média, que nos séculos XV e XVI se tornou o Estado administrativo, viu-se pouco a pouco "governamentalizado". (grifos do autor)

Logo se vê maquinarias de poder que apontam novas maneiras de governar. E nesse sentido, quando penso na emergência das Diretrizes Curriculares para a Educação Prisional (BRASIL, 2010) circunscrevo este documento como uma possibilidade de atuar sobre a população atendida, controlando-a. E tendo controle sobre os corpos, automaticamente controla também seus modos de ser e estar no mundo.

As falas dos presos nas entrevistas permitiram compreender como se instaura e se organiza uma política da Verdade para a modalidade da Educação de Jovens e Adultos e como esses discursos que se organizam como Verdadeiros compõem um currículo traiçoeiro. Traiçoeiro porque permite a construção da ideia de que a Educação está sendo oferecida enquanto um Direito até para cidadãos presos, mas não há preocupação com a qualidade do currículo desta oferta educativa. A qualidade do currículo como possibilidade de problematizar os espaços, tempos, significados do conhecimento e acima de tudo para que constitua um projeto que faça sentido à comunidade educacional. Entretanto, enquanto esse projeto não é construído, pouco importa o que lá dentro se faz, e nos alerta Maeyer (2013, p.42) que investir na educação prisional "não se trata de ajudar a passar o tempo ou fornecer uma educação pobre às pessoas pobres".

Sobre a utilização de materiais, a Diretriz em seu artigo $5^{\circ}$ coloca:

Os Estados, o Distrito Federal e a União, levando em consideração as especificidades da educação em espaços de privação de liberdade, deverão incentivar a promoção de novas estratégias pedagógicas, produção de materiais didáticos e a implementação de novas metodologias e tecnologias educacionais, assim como de programas educativos na modalidade Educação a Distância (EAD), a serem empregados no âmbito do sistema prisional (BRASIL, 2010, p.30).

Em conversa com os professores da rede estadual foi possível perceber que utilizam o mesmo livro didático que já estava no CR - Centro de Ressocialização, do semestre passado $\left(2^{\circ}\right.$ semestre/2012). Trata-se do mesmo livro em que os monitores-presos se apoiavam para suas aulas e trazem o seguinte comentário: "Eu uso o livro da EJA do $9^{\circ}$ ano para o Ensino Médio, não forço muito eles não". E me mostra uma cruzadinha que daria naquela aula e termina: "É meio infantil, mas foi o que achei pra hoje". Já, para outra professora a seleção é feita com base no critério considerado " $o$ básico para cada série". Os alunos durante as entrevistas também trouxeram suas questões sobre o livro didático utilizado. Vejamos: "as questão do livro lá .. só por Deus... ce ficava fritando a cabeça 
num barato que nem vai usar no seu dia a dia... não vai ampliar seu ritmo de vida" (Jhonatas) ou mesmo: "Pra falar a verdade dos livros que eu uso, só uso um livro que é o não lembro o nome, o verde $e^{5}$ lá... . você chegou a ver... eu tava olhando ali e tem coisa interessante, só que tem muito mais Português ali... Matemática tem muito pouco, e no caso aquelas contas de Matemática ali é da primeira série e eu to na quarta série." (Edmilson)

Para Silvio, sua percepção é a de que os livros didáticos: "são muito fraco, nossa! o conteúdo..acho que as próprias pessoas que fazem isso elas acham, já acredita que nois não sabemos nada... sabe... tem umas perguntas muito repetitivas, muito igual e são matérias de História... a gente estudou sobre os índios... tem coisa que dá pra ir muito mais a fundo do que simplesmente dizer que eles fazem artesanato... quando entrou na questão dos mamelucos, aquilo ali é coisa de muita profundidade, tem muita História aquilo ali e o livro te dá pouco conhecimento, é muito básico, se você realmente precisa do conteúdo deixa a desejar..."

As entrevistas realizadas trouxeram um mapa extenso, cheio de atalhos, percalços, desafios para se compreender o sentido que o conhecimento tem dentro de uma escola numa unidade prisional. O movimento imbricado de duas instituições em pleno funcionamento coloca em cheque o direito humano à educação. A prisão como instituição disciplinar e toda sua maquinaria de funcionamento não entende que a pena já é paga pelos presos através de sua privação de liberdade, mas os outros direitos, tais como o direito humano à educação deve ser garantido já que é preconizado por lei. Todavia, os desafios para a elaboração de um projeto político pedagógico que saia do papel devem priorizar:

A salutar complementaridade entre a legislação educacional e a penal (LDB e Execução Penal) favorece a articulação entre políticas setoriais (educação, trabalho, saúde, segurança pública, serviço social), potencializa a sinergia entre duas ciências (pedagogia e direito penitenciário) e mobiliza distintos campos profissionais (professores/agentes penitenciários) em torno de objetivos comuns (SILVA, 2011, p. 3).

Dentro da escola pesquisada, o currículo mostra-se também uma possível chave de regeneração do homem preso, não pelas vias do conhecimento, mas pela via da moralidade. Essa questão também foi apontada pelo Relator Especial da $\mathrm{ONU}^{6}$ (Organização das Nações Unidas), o costa riquenho Vernor Munoz. Ao destacar os modelos educativos predominantes dentro de prisões na América Latina, faz referência ao modelo que entende a educação prisional como "destinada a corrigir pessoas intrinsecamente imorais". Isto é explicado pelo monitor-preso Robinson quando diz que "o currículo deve formar pessoas que reconheçam algumas palavrinhas tais como honestidade, boa vontade, ética. Aqui eles não precisam só do aprender a ler e escrever, mas dessas coisas também".

Podemos então depreender que nas escolas da "rua", sua função é muitas vezes definida como a forma de prevenir a criminalidade e isto foi salientado por Patto (2007) quando trouxe como exemplo bordões de uma campanha para deputado federal do ano de 2006 em que a frase de efeito era então proclamada: "uma sala de aula a mais, uma cela a menos" (p. 244).

Mas e dentro da prisão? O que pode um currículo? A fala de Robinson nos aponta que o currículo deve buscar a ressocialização dos homens presos pela chave da transformação de suas condutas. E assim, a escola torna-se sempre um instrumento de algo, ainda me referindo aos modelos educativos apontados acima por Vernor Munoz (ou serve como terapia que busca a cura, ou transformar imorais, e ainda compreendida apenas como formação para o trabalho) e não como fundamental para o direito humano à formação e ao acesso aos bens culturais produzidos constantemente pela sociedade. Wellington (22 anos) faz referência em sua fala sobre a ideia de um currículo voltado para a ressocialização do homem preso quando aponta que: "Aqui dentro é ressocializar, né! Porque eu acho que é a parte que mais ressocializa é a escola... porque já tá preso... $\mathrm{Na}$ rua seria evoluir". Interessante notar que o sentido que Wellington atribui à escola dentro do cárcere se diferencia da "escola da rua", pois quando coloca que a escola dentro da prisão deve ressocializar possivelmente se refere aos modelos educativos já descritos acima (curar, corrigir condutas, explorar mão de obra barata).

Nas entrevistas, os presos foram solicitados a delinear expectativas com relação ao que a escola deveria atender em seus processos formativos. Com o gráfico abaixo, percebe-se que os cursos profissionalizantes assumem o eixo de suas expectativas no que a escola poderia atendê-los enquanto privados de sua liberdade. Verifica-se também como segunda opção de modelo educativo 
na percepção dos presos, a combinação entre a escola regular + curso profissionalizante e por último, o interesse pelo modelo educativo oferecido atualmente centrado nas disciplinas.

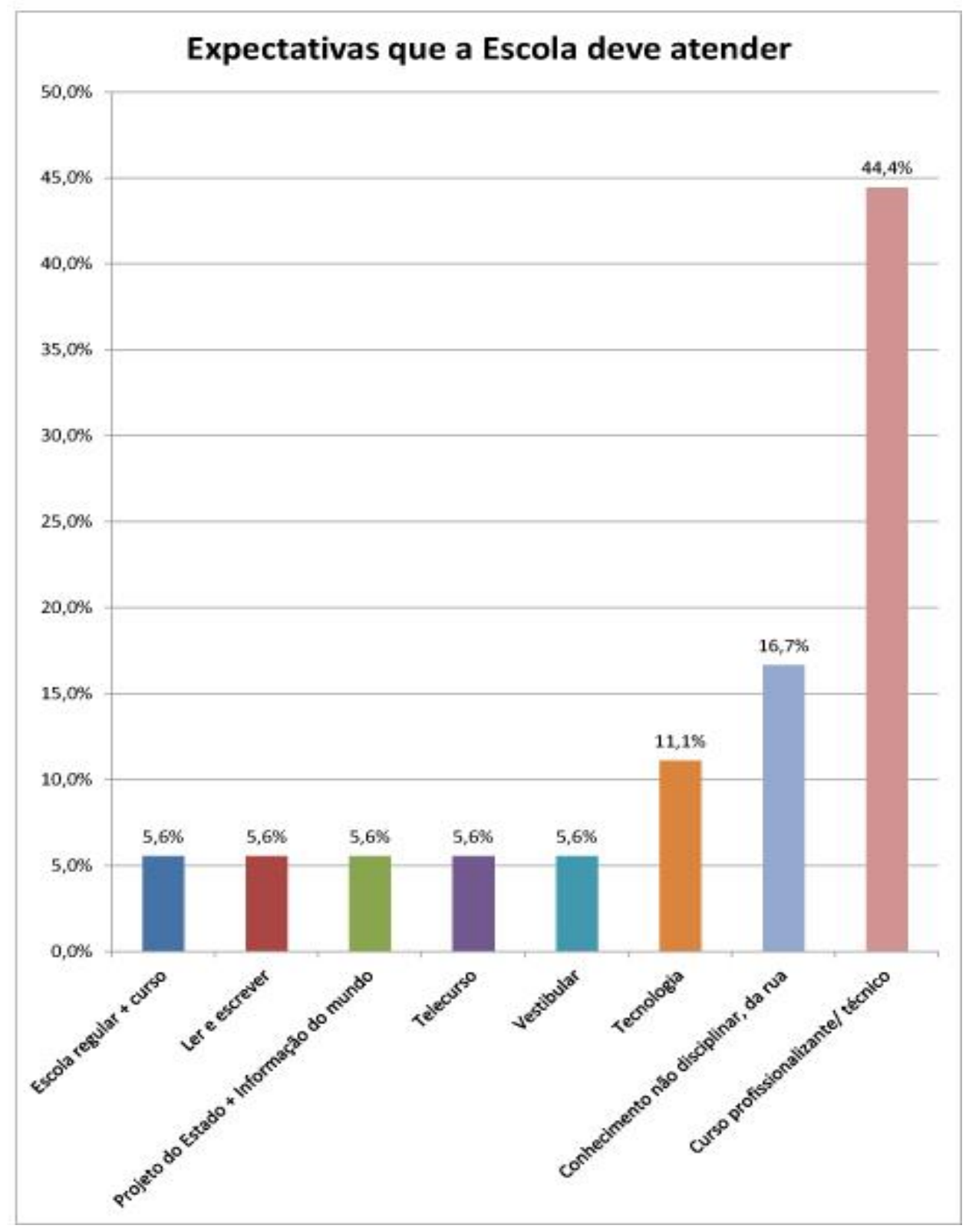

Apesar de falaciosa a relação entre a escolarização e a formação profissional como bases para a ascensão social, é preciso compreender a necessidade dos sujeitos privados de sua liberdade sem escolarização e sem certificação profissional e, assim, o anseio de que o tempo de cumprimento da pena colabore para sua saída para o "mundão" (como dizem) em melhores condições.

\section{Possíveis contornos}

Verifica-se, portanto mais uma vez que a instituição escolar nega à população pesquisada o direito humano à Educação e uma possibilidade de conhecimento através dos bens culturais. Essa mesma negação também foi trazida pelos presos durante as entrevistas em que colocaram suas trajetórias escolares estritamente vinculadas apenas à certificação.

A pesquisa também aponta para a necessidade de que a Educação Prisional não seja apenas a responsabilidade burocrática da Secretaria Estadual de Educação. Através das entrevistas dos alunos em situação de privação de liberdade evidencia-se a fundamental articulação com outras Secretarias (Justiça, Trabalho, Assistência Social, 
Saúde e etc...) para compor o trabalho pedagógico. Desta maneira, o que nos dizem é que a reprodução de um modelo educativo da "rua" não atende seus anseios na possibilidade de um papel para a escola dentro do cárcere que promova situações com sentido a esses jovens e adultos que, por diferentes motivos, interromperam suas trajetórias escolares muito cedo.

A maneira como a Secretaria da Educação do Estado de São Paulo vem assumindo sua responsabilidade para com a educação nas prisões não tem favorecido a montagem de quadros estáveis de professores que garanta a elaboração e execução de um projeto político pedagógico para a unidade prisional. Alterando-se o quadro de professores quase que semestralmente através dos contratos temporários, é impossível pensar numa proposta de formação que se torna uma grande lacuna com efeitos na prática pedagógica realizada.

$\mathrm{O}$ fato de coexistirem dentro do mesmo espaço: prisão e escola com propósitos tão divergentes e opostos são questões centrais que devem perseguir a formulação de políticas públicas. Tanto a prisão quanto a escola são mantidas pelo Estado, todavia cada uma desempenhando uma função na vida dos apenados. O fortalecimento de um conjunto de profissionais que atuam dentro do cárcere somados aos educadores pode ser uma possibilidade para a realização do debate que envolve re(pensar) o sentido da pena da prisão, bem como os objetivos pretendidos pela Execução Penal através da Educação.

Enquanto o entendimento do currículo for restrito apenas à vida dentro da sala de aula, o processo educativo oferecido pelo Estado para essa população permanece mais uma vez assentado na negação de direitos. Sendo a educação no cárcere entendida como regalia e não como direito, o processo educativo permanece fundado apenas na lógica da certificação e não como possibilidade de entrar em contato com a re(construção) de sua própria história através da apropriação aos bens culturais como forma de conhecimento.

\section{Notas}

1 www.justica.gov.br

2 www.saopaulo.sp.gov.br

3 Disponível em www.sap.sp.gov.br (acesso em 18/07/2012).

4 Disponível em www.observatoriodeseguranca. org.br (acesso em 19/07/2012).
5 Coleção Tempo de Aprender. Vol. 3. Multidisciplinar EJA - $6^{\circ}$ ao $9^{\circ}$ ano do Ensino Fundamental. Ed. IBEP e Base Editorial. $2^{\mathrm{a}}$ ed. 2012.

6 Trata-se da seção: "Os modelos educativos e a ressocialização" que faz parte do Relatório sobre Educação nas prisões brasileiras, elaborado por Denise Carreira (2009), já citado em outras partes da pesquisa. (Plataforma Brasileira de Direitos Humanos, Econômicos, Sociais, Culturais e Ambientais. Plataforma DhESCA Brasil).

\section{Interlocutores}

ADORNO, S. A prisão sob a ótica de seus protagonistas. Itinerário de pesquisa. Tempo Social. Revista de Sociologia da USP. São Paulo. v. 3, n. 1 e 2, 1991, p7-40.

BAUMAN, Z. Vidas Desperdiçadas. Rio de Janeiro: Jorge Zahar, 2007.

Tempos Líquidos. Rio de Janeiro:

Jorge Zahar, 2008.

BEZERRA, P... Polifonia. In: BRAIT, B. (Org.). Bakhtin: conceitos-chave. Rio de Janeiro: Contexto, 2005, p. 194.

BRASIL. Conselho Nacional de Política Criminal e Penitenciária. Resolução $n^{o} 3$, de 11 de março de 2009. Dispõe sobre as Diretrizes Nacionais para a Oferta de Educação nos estabelecimentos penais. Brasília: CNPCP, 2009.

BRASIL. Ministério da Educação. Conselho Nacional de Educação. Câmara Nacional de Educação Básica. Resolução $n^{\circ} 2$, de 19 de maio de 2010. Dispõe sobre as Diretrizes Nacionais para a oferta de educação para jovens e adultos em situação de privação de liberdade nos estabelecimentos penais. Brasília: MEC, CNE, CNEB, 2010.

BRASIL. Ministério da Educação. Conselho Nacional de Educação. Diretrizes Nacionais para a oferta de Educação para Jovens e Adultos em situação de privação de liberdade nos estabelecimentos penais. MEC, CNE, 2010.

BRASIL. Ministério da Justiça. Departamento 
Penitenciário Nacional. Sistema Integrado de Informações Penitenciárias. (INFOPEN).

Disponível em <www.mj.gov.br.>. Acesso em: 20/12/2014.

FOUCAULT, M. Microfísica do poder. 26. ed. Rio de Janeiro: Editora Graal, 2008.

FOUCAULT, M. Vigiar e punir: o nascimento da prisão. 38 ed. Petrópolis: Vozes, 2010.

JULIÃO, E. F. A ressocialização através do estudo e do trabalho no sistema penitenciário brasileiro.

Rio de Janeiro, 2009. 433f. Tese (Doutorado em Ciências Sociais). Instituto de Filosofia e Ciências Humanas, Universidade do Estado do Rio de Janeiro, Rio de Janeiro, 2009.

LOPES, A. C. Discursos nas políticas de currículo. Currículo sem fronteiras, v.6, n. 2, jul/dez. 2006., p. 33-52.

MAEYER, M. D. A educação na prisão não é mera atividade. Revista Educação \& Realidade. Porto Alegre, v. 38, n. 1, jan-mar. 2013, p.33-49.

PASSOS, E.; KASTRUP, V.; ESCÓSSIA, L. (Orgs). Pistas do método da cartografia. Pesquisaintervenção e produção de subjetividade. Porto Alegre: Sulina, 2009.
PATTO, M. H. S. Escolas cheias, cadeias vazias. Nota sobre as raízes ideológicas do pensamento educacional brasileiro. Revista Estudos Avançados, São Paulo, v. 21, n. 61, 2007, p. 243-266.

SÃO PAULO, SAP/SEE. Decreto $n^{\circ} 57.238$, de 17 de agosto de 2011. Institui o Programa de Educação nas Prisões e dá providências correlatas. São Paulo: SAP/SEE, 2011.

SAUSSURE, F. Curso de Linguística Geral. 28. ed. São Paulo: Cultrix, 2000.

SILVA, R.; MOREIRA, F. A. O projeto político pedagógico para a educação em prisões. Revista Em Aberto, Brasília, v. 24, n. 86, nov. 2011.

TÜRCKE, Christoph. Sociedade Excitada- filosofia da sensação. Campinas, SP. Editora da UNICAMP, 2010.

UNESCO. OEI. Educação em prisões na América Latina: direito, liberdade e cidadania. Brasília: UNESCO, OEI, AECID, 2009.

VEIGA-NETO, A; CORCINI, M. Inclusão e governamentalidade. Revista Educação e Sociedade, Campinas, v. 28, n.100, out. 2007, p. 947-963.

\section{Sobre a autora}

Cátia Alvisi é Doutora em Educação pela Universidade Estadual de Campinas- UNICAMP, na Área de Ensino e Práticas Culturais. Pesquisadora do Laboratório sobre Violência, Cultura e Juventude. (VIOLAR). Professora de Língua Portuguesa de Ensino Fundamental II e coordena projetos envolvendo a formação de professores de rede pública.

Recebido em agosto de 2016.

Aprovado em novembro de 2016. 